\title{
Effect of Processing Parameters on Microstructure and Mechanical Properties in High Temperature Deformation of Ti-6Al-4V Alloy
}

\author{
Yu Weixin, Li Miaoquan, Luo Jiao \\ Northwestern Polytechnical University, Xi'an 710072, China
}

\begin{abstract}
The effect of the deformation temperature, deformation degree, strain rate and their interaction on the microstructure and mechanical properties in the high temperature deformation of Ti-6Al-4V alloy was investigated. The experimental results show that the deformation degree and strain rate have significant influence on the microstructure and mechanical properties, in which finer microstructure and higher tensile strength can be obtained at a middle deformation degree and a higher strain rate. The interactions between the deformation temperature and the deformation degree or the strain rate in the high temperature deformation of Ti-6Al-4V alloy are significant, especially being deformed at the temperature just under the $\beta$ transus, the ductility and tensile strength are sensitive to all of processing parameters including their interactions. So the interactions should be considered to optimize the processing parameters in order to meet the requirements of the mechanical properties.
\end{abstract}

Key Words: Ti-6Al-4V alloy; processing parameters; microstructure; mechanical properties

Microstructures of titanium alloys are very sensitive to processing parameters, and the desired microstructure can be obtained at the proper processing parameters to obtain good mechanical properties such as strength, ductility, toughness, fatigue resistance and so on ${ }^{[1-8]}$. A large number of studies on deformation mechanism of titanium alloys are available in the literature. Mythili et al ${ }^{[9]}$ studied the deformation mechanism of Ti-4.4Ta-1.9Nb alloy by means of TEM and found that the $\alpha$ phase deformed predominantly by slip although twinning was also observed occasionally and the $\beta$ particles do not act as effective barriers for the dislocation movement. Glavicic et $\mathrm{al}^{[10]}$ reported that prism slip is considerably easier to activate in the $\alpha$ phase than basal slip during hot working of Ti-6Al-4V alloy. Ma et al ${ }^{[11]}$ studied microstructure evolution of Ti-1100 alloy during thermomechanical processing and found that the $\beta$ phase prefers to recrystallize at the junction of the boundary of the $\beta$ grains during deformation in the $\beta$ phase field. Li et $\mathrm{al}^{[12]}$ studied processing parameters of the microstructure of Ti-15-3 alloy and found that the grain size of the primary $\alpha$ phase increases with raising of deformation temperature but decrease with increasing of deformation degree and strain rate. Sha et $\mathrm{al}^{[13]}$ studied the effect of deformation temperature on mechanical properties of TC18 alloy and found that ultimate strength remains at about $1200 \mathrm{MPa}$ with increasing of deformation temperature, and impact and fracture toughness are sensitive to the deformation temperature.

However, there are few studies on the interaction between the processing parameters by now. The hot deformation of titanium alloys is a mutual coupling process of deformation behaviour, heat transfer and microstructure evolution ${ }^{[14-17]}$. Hence, deformation temperature, deformation degree, strain rate and their interactions should be treated as a function of processing parameter.

Ti-6Al-4V alloy is characterized as $\alpha$ rich $\alpha+\beta$ titanium alloy, and is widely used in the aerospace industry for both engine and frame applications due to its low density, high strength, toughness, good high temperature properties and formability. Because of most of the bulk metal working processes being conducted under compression stress, the effects of processing parameters on microstructure and 
mechanical properties in the high temperature deformation of Ti-6Al-4V alloy has been investigated by means of compression tests to provide the technological basis for optimizing processing parameters in the present study.

\section{Experimental}

The as received Ti-6Al-4V alloy was a hot-rolled bar stock with $90 \mathrm{~mm}$ in diameter. The heat treatment procedure prior to isothermal compression was as follows: heated to $750{ }^{\circ} \mathrm{C}$ and held for $1.5 \mathrm{~h}$, cooled in air to room temperature. The microstructure of Ti-6Al-4V alloy after the heat treatment is shown in Fig.1. Its chemical composition (in weight percent) was $6.5 \mathrm{Al}, 4.25 \mathrm{~V}, 0.04 \mathrm{Fe}, 0.02 \mathrm{C}, 0.16 \mathrm{O}, 0.015 \mathrm{~N}, 0.0018$ $\mathrm{H}$ and balance $\mathrm{Ti}$. The $\beta$ transus for this material was approximately $995^{\circ} \mathrm{C}$.

The test parameters consisted of deformation temperatures of $850,900,950$ and $980{ }^{\circ} \mathrm{C}$, deformation degree of $35 \%$, $50 \%$ and $65 \%$, and strain rates of $1.73 \times 10^{-3}$ and $1.73 \times 10^{-1} \mathrm{~s}^{-1}$. The dimensions of the specimens with $68 \mathrm{~mm} \times 12 \mathrm{~mm} \times 18$ $\mathrm{mm}, 68 \mathrm{~mm} \times 12 \mathrm{~mm} \times 24 \mathrm{~mm}$ and $68 \mathrm{~mm} \times 12 \mathrm{~mm} \times 32 \mathrm{~mm}$ corresponded to the deformation degree of $35 \%, 50 \%$ and $65 \%$, respectively. The compression tests were carried out at a $2500 \mathrm{t}$ isothermal hydrostatic machine. The specimens were coated with a borosilicate glass paste for lubrication and environmental protection.

After isothermal compression, the specimens were air-cooled rapidly to room temperature, sectioned parallel to the compression axis from one side of the deformed specimens and the cut surface of the smaller part was prepared for metallographic examination using standard procedures.

The bigger part of the deformed specimens was annealed at $720{ }^{\circ} \mathrm{C}$ for $60 \mathrm{~min}$ and air-cooled. Tensile samples had $5 \mathrm{~mm}$ in diameter and $25 \mathrm{~mm}$ in gauge length. Tensile tests were carried out using a ZWICK/Z150 test machine at room temperature and at a constant cross-head speed of $2 \mathrm{~mm} / \mathrm{min}$. Ultimate tensile strength $\left(\sigma_{\mathrm{b}}\right), 0.2 \%$ proof stress $\left(\sigma_{0.2}\right)$, reduction in area $(\psi)$ and elongation $(\delta)$ were measured.

\section{Results and discussion}

\subsection{Effect of processing parameters on microstructure}

\subsubsection{Deformation temperature}

In $\alpha+\beta$ two-phase area, the effect of deformation temperature on microstructure is significant. At a deformation degree of $65 \%$ and strain rate of $1.73 \times 10^{-1} \mathrm{~s}^{-1}$, the microstructure varies with deformation temperature, shown in Fig.2.

The deformation temperature has an obvious effect on the volume fraction and grain size of the primary $\alpha$ phase. The volume fraction of the primary $\alpha$ phase decreases with increasing of deformation temperature in the range from 850 ${ }^{\circ} \mathrm{C}$ to $950{ }^{\circ} \mathrm{C}$ because of the $\alpha+\beta \rightarrow \beta$ transformation. On the other hand, higher temperature enhances the diffusion process greatly, and the merging trend of the adjacent $\alpha$ grains increases with increasing of deformation temperature so that the primary $\alpha$ grain size does not significantly vary with increasing of deformation temperature in the range from 850 to $950{ }^{\circ} \mathrm{C}$. The micrograph of the specimen deformed at a deformation temperature of $980^{\circ} \mathrm{C}$ exhibits significant change compared with that deformed at lower deformation temperatures. The volume fraction of primary $\alpha$ phase is less than a half and the grain size of primary $\alpha$ phase decreases sharply at a deformation temperature of $980^{\circ} \mathrm{C}$ compared with that deformed at deformation temperatures less than $950{ }^{\circ} \mathrm{C}$.

In the deformation temperature range from 850 to $950^{\circ} \mathrm{C}$, the primary $\alpha$ grains exist in two morphologies: one is equiaxed grains resulted from dynamic recrystallization and another as plates which is a typical recovery structure. The amount of the recovery structure decreases and the equiaxed grains increases at a deformation temperature of $980{ }^{\circ} \mathrm{C}$

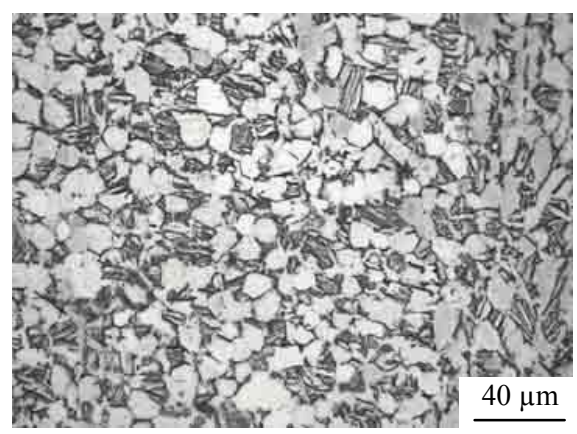

Fig.1 Micrographs of as received Ti-6Al-4V alloy

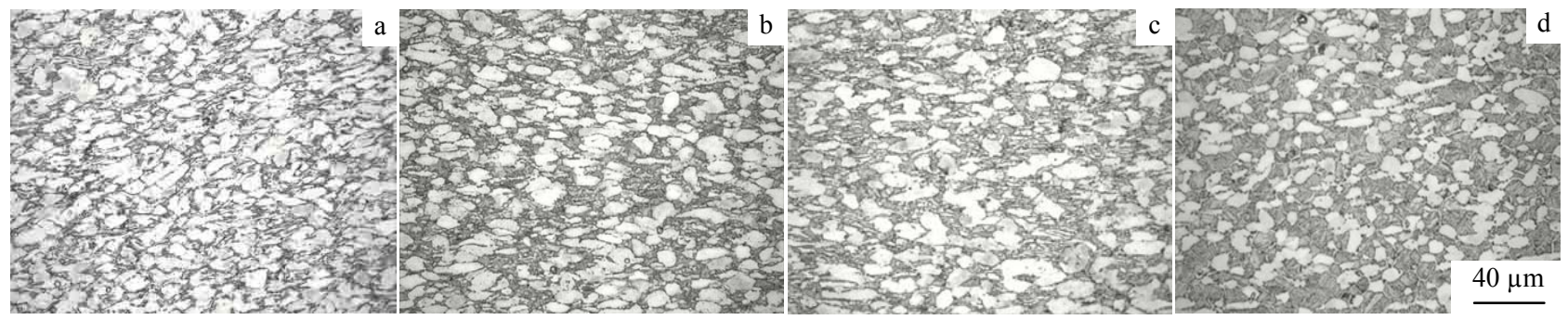

Fig.2 Micrographs of the Ti-6Al-4V alloy deformed at a deformation degree of $65 \%$, strain rate of $1.73 \times 10^{-1} \mathrm{~s}^{-1}$ and different deformation temperatures of (a) $850{ }^{\circ} \mathrm{C}$, (b) $900{ }^{\circ} \mathrm{C}$, (c) $950{ }^{\circ} \mathrm{C}$, and (d) $980^{\circ} \mathrm{C}$ 
Rare Metal Materials and Engineering

Volume 38, Issue 1, January 2009

Online English edition of the Chinese language journal
Available online at www.sciencedirect.com ScienceDirect

Cite this article as: Rare Metal Materials and Engineering, 2009, 38(1): 0019-0024.

compared with that at the deformation temperatures ranging from 850 to $950{ }^{\circ} \mathrm{C}$ resulting in the easier occurrence of dynamic recrystallization at higher deformation temperature ${ }^{[18,19]}$

It can be seen from Fig. $2 \mathrm{a}-2 \mathrm{c}$ that the secondary $\alpha$ phase shows as little grains or short platelets and distributes disorderly at lower deformation temperatures. Microstructure examination of the Ti-6Al-4V alloy deformed at a deformation temperature of $980{ }^{\circ} \mathrm{C}$ in Fig. $2 \mathrm{~d}$ reveals the presence of secondary $\alpha$ lamellar colony structure. The reason is that the heat activation is enhanced greatly and the dynamic recovery of the $\beta$ phase is sufficient at higher temperature, and so the dislocation density in the $\beta$ phase decreases with increasing of deformation temperature. The grain boundary and dislocation in the $\beta$ phase are the nucleation locations of secondary $\alpha$ precipitates. At lower deformation temperatures, the precipitate number density is higher than that at higher deformation temperatures resulting in the variation of secondary $\alpha$ phase morphology with deformation temperature.

\subsubsection{Deformation degree}

At a deformation temperature of $980{ }^{\circ} \mathrm{C}$ and strain rate of $1.73 \times 10^{-1} \mathrm{~s}^{-1}$, microstructure variation with deformation degree is shown in Fig.3.

It can be seen from Fig. 3 that the primary $\alpha$ grains of the Ti-6Al-4V alloy deformed at the deformation degree of $35 \%$ exhibit flat morphology vertically to compression axis. At the deformation degrees of $50 \%$ and $65 \%$, the primary $\alpha$ grains exist in two morphologies of equiaxed and platelet, which means the partly dynamic recrystallization occurred in primary $\alpha$ grains. The high temperature compression deformation mechanism of titanium alloy consists of dislocation sliding, dislocation climbing, and some twining in $\alpha$ phase, so dislocation density and distortion energy increase sharply with increasing of deformation degree ${ }^{[20-22]}$. In the deformation process, the primary $\alpha$ grains were flattened, distorted and broken-up with increasing of deformation degree and the part primary $\alpha$ phase recrystallized dynamically at the same time. At the deformation degree of $65 \%$, some primary $\alpha$ grains are very large resulting from the difference of distortion energy between the primary $\alpha$ grains. The distortion energy of primary $\alpha$ grains is accumulated being induced by the plastic deformation and decreases subsequently to as low as being recystallized. Two primary $\alpha$ grains with higher and lower distortion energy are easy to merge when they are adjacent and the kinetics is primarily the difference of their distortion energy and partly be attributed to the decreasing of total interfacial energy.

The morphology and distribution of secondary $\alpha$ phase exhibit significant changes with increasing of deformation degree from $35 \%$ to $50 \%$. At the deformation of $35 \%$, the secondary $\alpha$ phase exhibits a thin lamellar colony structure, but at the deformation degrees of $50 \%$ and $65 \%$, the secondary $\alpha$ phase shows as little grains or short platelets and distributs disorderly, which is also caused by the difference of the dislocation density in the $\beta$ phase just after deformation.

\subsubsection{Strain rate}

At a deformation temperature of $980{ }^{\circ} \mathrm{C}$ and deformation degree of $65 \%$, microstructure variation with strain rate is shown in Fig.4. It can be seen from Fig.4 that the strain rate has no evident influence on the volume fraction but affects the grain size and morphology of the primary $\alpha$ phase significantly. At higher strain rates, one part of primary $\alpha$ grains shows as equiaxed resulted from dynamic recrystallization, and the others show as the plates having a typical recovery structure. Dynamic recrystallization and dynamic recovery are two contradictory processes but exist simultaneously at most conditions. In general, it is difficult to occur for dynamic recovery and dynamic recrystallization simultaneously in the plastic deformation processe because the distortion energy releases through dynamic recovery and is accumulated difficultly to the level for dynamic recrystallization. Dislocation density, distortion energy and recrystallization locations increase with increasing of strain rate and so dynamic recrystallization is easy to occur at higher strain rates ${ }^{[23,24]}$. On the other hand, deformation time decreases sharply with increasing of strain rate, and a great amount of primary $\alpha$ grains does not conduct dynamic recrystallization because of no enough time at higher strain rates. At lower strain rates, most of primary $\alpha$ grains show as equiaxed and a certain extent of growth and coarsening appears. It is because a few recrystallized nucleation can also occur in the de

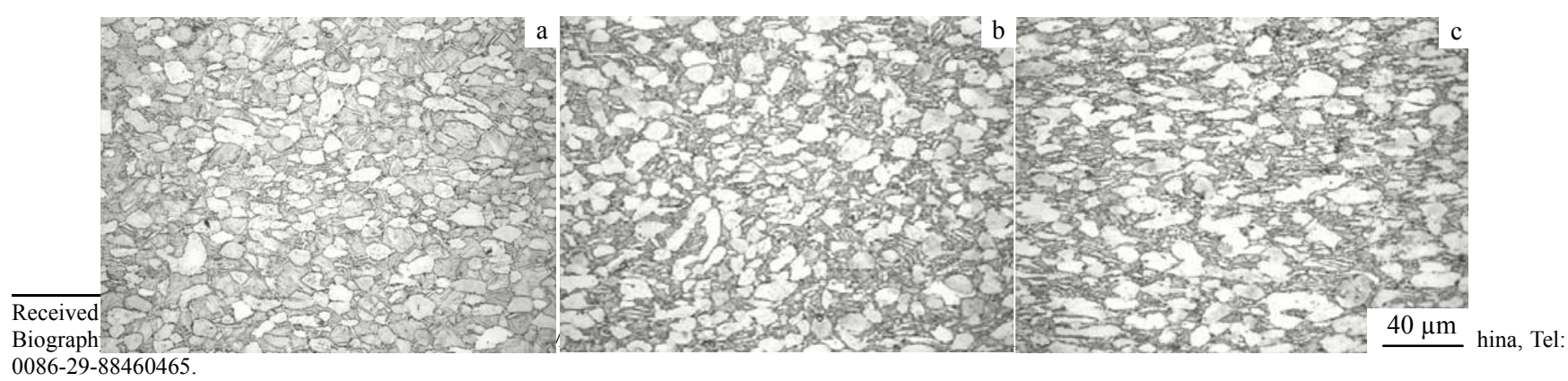




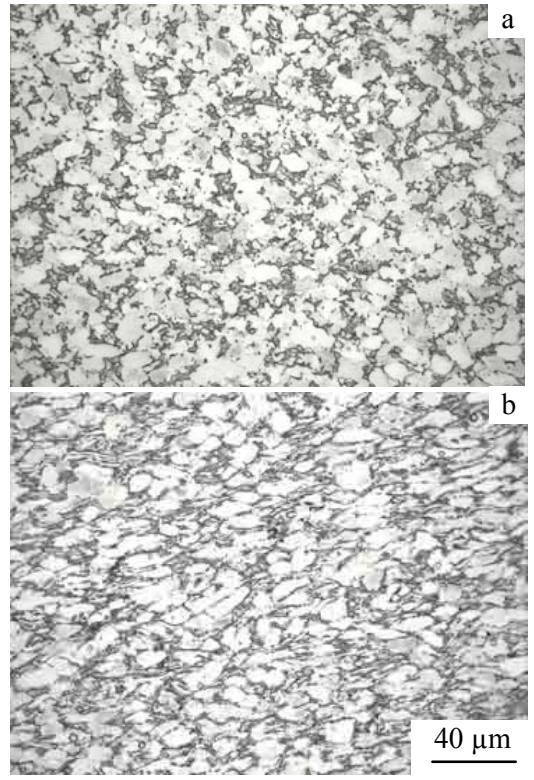

Fig.4 Micrographs of the Ti-6Al-4V alloy deformed at a deformation temperature of $8500^{\circ} \mathrm{C}$, deformation degree of $65 \%$ and different strain rates of (a) $1.73 \times 10^{-3} \mathrm{~s}^{-1}$ and (b) $1.73 \times 10^{-1} \mathrm{~s}^{-1}$

formation process and there is enough deformation time for
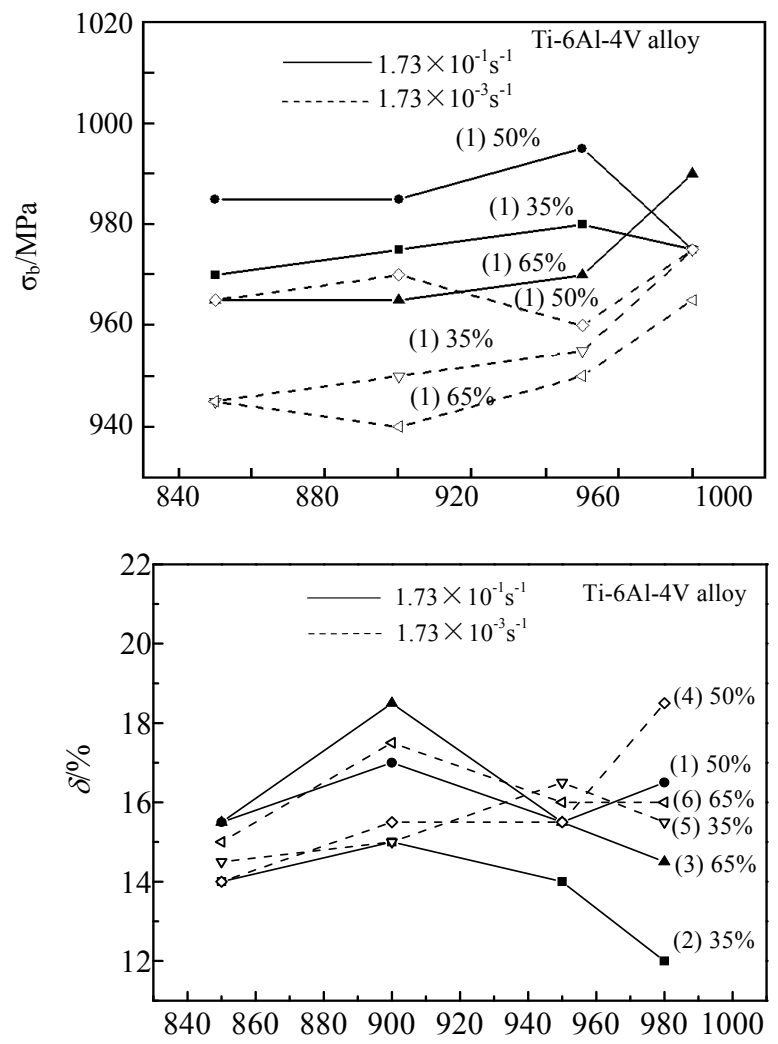

Deformation Temperature $/{ }^{\circ} \mathrm{C}$ the growth of the crystal nucleus although the dynamic recrystallization is difficult to occur at lower strain rates [22-26]

\subsection{Effect of processing parameters on mechanical properties}

The effect of processing parameters on mechanical properties including ultimate tensile strength $\left(\sigma_{\mathrm{b}}\right), 0.2 \%$ proof stress $\left(\sigma_{0.2}\right)$, reduction in area $(\psi)$ and elongation $(\delta)$ is shown in Fig.5. It can be seen from Fig.5 that $\sigma_{\mathrm{b}}$ and $\sigma_{0.2}$ have no evident change with increasing of the deformation temperatures in the range from 850 to $950{ }^{\circ} \mathrm{C}$ and it means that the strength is not sensitive to the deformation temperature in the range from 850 to $950{ }^{\circ} \mathrm{C} . \delta$ increases to a peak value at the deformation temperature of $900{ }^{\circ} \mathrm{C}$ and then decreases with increasing of the deformation temperatures from 850 to $950{ }^{\circ} \mathrm{C}$, and $\psi$ decreases to a minimum value at the deformation temperature of $900{ }^{\circ} \mathrm{C}$ and then increases with increasing of deformation temperatures from 850 to $950{ }^{\circ} \mathrm{C}$.

The deformation degree and strain rate affect significantly the $\sigma_{\mathrm{b}}$ and $\sigma_{0.2}$ in the deformation temperature range from 850 to $950{ }^{\circ} \mathrm{C}$. Fig. $5 \mathrm{a}$ and $5 \mathrm{~b}$ show that $\sigma_{\mathrm{b}}$ and $\sigma_{0.2}$ increase to a peak value at the deformation degree of $50 \%$ and then decrease with increasing of the deformation degrees from $35 \%$ to $65 \% . \sigma_{\mathrm{b}}$ and $\sigma_{0.2}$ increase significantly with increasing of strain rate. It can be concluded that the mechanical properties
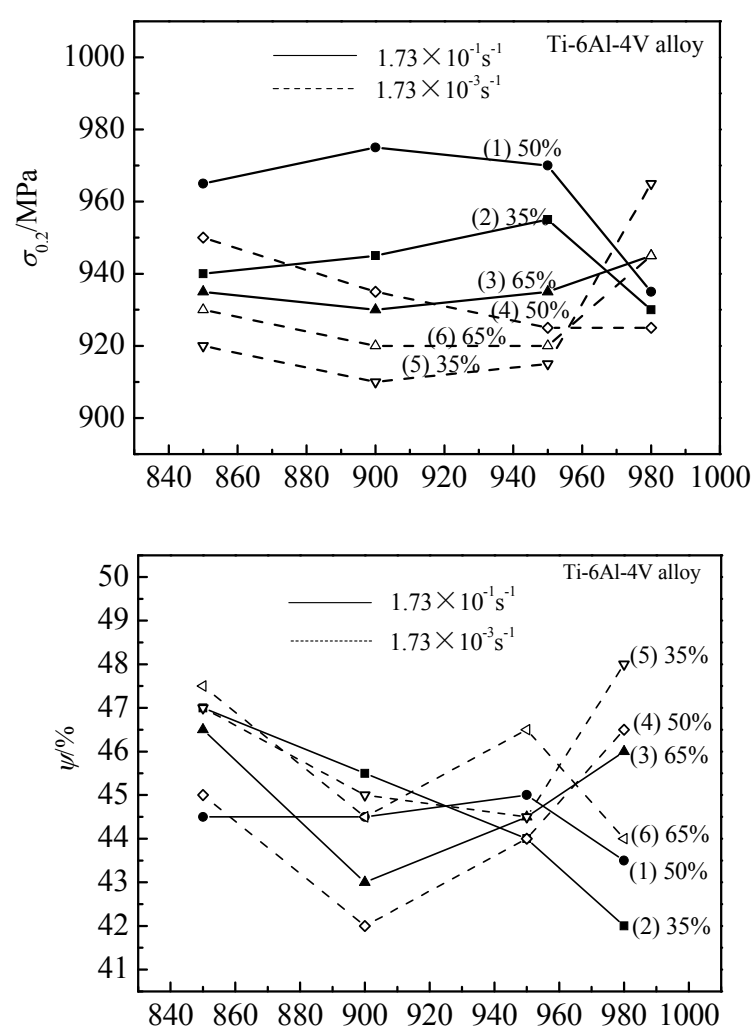

Deformation Temperature $/{ }^{\circ} \mathrm{C}$ 
of the Ti-6Al-4V alloy are sensitive to the primary $\alpha$ grain size as finer microstructure has higher mechanical properties.

In the deformation temperature range from 950 to $980{ }^{\circ} \mathrm{C}$, the interaction of the processing parameters is very significant. It can be seen from Fig.5a and $5 \mathrm{~b}$ that curves (1) and (2) trend lowering but curve (3) trends rising with increasing of deformation temperature from 950 to $980{ }^{\circ} \mathrm{C}$, which means that the interaction between deformation temperature and deformation degree is significant. There is also significant interaction between deformation temperature and strain rate shown in Fig.5a and 5b, i. e. curve (1) trends lowering but curve (4) trends rising with increasing of deformation temperature in the range from 950 to $980{ }^{\circ} \mathrm{C}$. At the deformation temperature of $980{ }^{\circ} \mathrm{C}$ and strain rate of $1.73 \times$ $10^{-1} \mathrm{~s}^{-1}, \sigma_{\mathrm{b}}$ of the Ti-6Al-4V alloy deformed at a deformation degree of $65 \%$ is higher but at the deformation temperature of $980{ }^{\circ} \mathrm{C}$ and strain rate of $1.73 \times 10^{-3} \mathrm{~s}^{-1}, \sigma_{\mathrm{b}}$ of the Ti- $6 \mathrm{Al}-4 \mathrm{~V}$ alloy deformed at the deformation degree of $35 \%$ is higher, which means the interaction between

deformation degree and strain rate is significant at the deformation temperature near the $\beta$ transus. From above analysis, it is concluded that a higher strain rate corresponds to a larger desired deformation degree and a lower strain rate corresponds to a smaller desired deformation degree at the deformation temperatures just under the $\beta$ transus.

The effect of the interaction of processing parameters on mechanical properties of the Ti-6Al-4V alloy can be explained from microstructure evolution. At the deformation temperature just under the $\beta$ transus, thermally activated process is greatly enhanced and adiabatic temperature rise has a great effect on the primary $\alpha$ volume fraction. The deformation at a higher deformation degree and strain rate would cause significantly adiabatic temperature rise, which in turns cause the volume fraction and grain size of the primary $\alpha$ phase to decrease sharply, so the ductility and tensile strength are at higher levels. The deformation at a smaller deformation degree and a lower strain rate can prolong the deformation time, and part of the primary $\alpha$ grains has enough time to refine through dynamic recrystallization, so a lower strain rate is needed when the desired deformation degree is smaller at the deformation temperatures just under the $\beta$ transus.

\section{Conclusions}

1) In the $\alpha+\beta$ two-phase area, the primary $\alpha$ volume fraction decreases with increasing of deformation temperature. At the deformation temperature just under the $\beta$ transus, the deformation temperature has a significant effect on the morphology of primary $\alpha$ phase and secondary $\alpha$ phase. The morphology and distribution of primary $\alpha$ and secondary $\alpha$ phase exhibit significant changes with deformation degree, and the deformation degree of $50 \%$ can lead to a finer microstructure. The strain rate affects the morphology and grain size of primary $\alpha$ phase significantly, and higher strain rates would result in a finer microstructure.

2) The strain rate and deformation degree have significant influence on tensile strength in the deformation temperature range from 850 to $950{ }^{\circ} \mathrm{C}$. Tensile strength increases with increasing of strain rate, and increases first but then decreases with a peak value at $50 \%$ with increasing of deformation degree.

3) At the deformation temperature just under the $\beta$ transus, the interaction among the processing parameters is very significant, and a higher strain rate is needed when the desired deformation degree is larger and lower strain rate is needed when the desired deformation degree is smaller.

\section{References}

1 Hong Quan( 洪权 ) et al. Rare Metal Materials and Engineering(稀有金属材料与工程)[J], 2005, 34(8): 1334

2 Niu Yong, Hou Hongliang, Li Miaoquan et al. Materials Science and Engineering [J], 2008, A492(1/2): 24

3 Li Miaoquan, Pan Hongsi, Lin Yingying et al. Journal of Materials Processing Technology[J], 2007, 183(1): 71

4 Zhang M, Zhang J, McDowell D L. International Journal of Plasticity[J], 2007, 23: 1328

5 Xiong Aiming(熊爱明) et al. Rare Metal Materials and Engineering(稀有金属材料与工程) [J], 2003, 32(6): 447

6 Xiong Aiming, Li Miaoquan, Huang Weichao et al. Materials Science and Technology[J], 2004, 20(10): 1256

7 Li Miaoquan, Xiong Aiming, Chen Shenghui et al. Rare Metals[J], 2004, 23(3): 263

8 Leyens C, Peters M. Translated by Chen Zhenhua(陈振华). Titanium and Titanium Alloys( 钛及钛合金)[M]. Beijing: Chemical Industry Press, 2005: 11

9 Mythili R, Saroja S, Vijayalakshmi M et al. Materials Science and Engineering[J], 2007, (A454 455): 43

10 Glavicic M G, Semiatin S L. Acta Materialia[J], 2006, 54: 5337

11 Ma Fengcang, Lu Weijie, Qin Jining et al. Materials Science and 
Engineering[J], 2006, A 416: 59

12 Li Ping(李 萍) et al. Acta Metall Sin(金属学报)[J], 2002, 38: 145

13 Sha Aixue(沙爱学) et al. The Chinese Journal of Nonferrous Metals(中国有色金属学报)[J], 2005, 5(8): 1167

$14 \mathrm{Xu}$ X J, Lin J P, Wang Y L et al. Materials Science and Engineering [J], 2006, A416: 98

15 Kim J H, Semiatinb S L, Lee C S. Materials Science and Engineering[J], 2005, A394: 366

16 Li Miaoquan, Xiong Aiming, Huang Weichao et al. Materials Characterization[J], 2003, 49: 203

17 Bruschia S, Poggiob S, Quadrinib F et al. Materials Letters[J], 2004, 58: 3622

18 Ding R, Guo Z X, Wilson A. Materials Science and Engineering[J], 2002, A327: 233
19 Yapici G G, Karaman I, Luo Z P. Acta Materialia[J], 2006, 54: 3755

20 Mythili R, Saroja S, Vijayalakshmi M. Materials Science and Engineering [J], 2007, (A454 455): 43

21 Yao Zekun( 姚泽坤) et al. Rare Metal Materials and Engineering(稀有金属材料与工程)[J], 2000, 29(5): 340

22 Semiatin S L, Bieler T R. Acta Materialia[J], 2001, 49: 3565

23 Warchomicka F, Stockinger M, Degischer H P. Journal of Materials Processing Technology[J], 2006, 177: 473

24 Seetharaman V, Semiatin S L. Metallurgical and Materials Transactions[J], 2002, A 33: 3817

25 Bruschi S, Poggio S, Quadrini F et al. Materials Letters[J], 2004, 58: 3622

26 Ivasishin O M, Shevchenko S V, Vasiliev N L et al. Materials Science and Engineering[J], 2006, A433: 216

\title{
变形工艺参数对 Ti-6Al-4V 钛合金组织和性能的影响
}

\author{
于卫新, 李永泉, 罗 犋 \\ (西北工业大学，陕西 西安 710072)
}

\begin{abstract}
摘 要: 研究了变形温度、变形程度、应变速率以及三者之间两两交互作用对Ti-6Al-4V钛合金组织和力学性能的影响。结果表明: 变 形程度和应变速率对力学性能的影响比较显著, 在中等变形程度和较大的应变速率下成形时微观组织较为细小均匀, 可以获得较高的抗 拉强度和屈服强度; 但工艺参数间的交互作用不容忽视，在变形温度稍低于相变点时，工艺参数间的交互作用对强度和塑性的影响显著。 因此，优化成形工艺参数应根据强度、塑性等性能指标的要求，在考虑工艺参数间交互作用的基础上进行。
\end{abstract}

关键词：Ti-6Al-4V钛合金；工艺参数；交互作用；微观组织；力学性能 